\title{
Kajian Penataan dan Efisiensi Ruang Dalam Renovasi Rumah Tinggal
}

\author{
Baharudin Yusuf Subagya, Aprodita Emma Yetti \\ Program Studi Arsitektur, Fakultas Sains Dan Teknologi, Universitas 'Aisyiyah Yogyakarta \\ Program Studi Arsitektur, Fakultas Sains Dan Teknologi, Universitas 'Aisyiyah Yogyakarta \\ Email: rudisubagya021@gmail.com
}

\begin{abstract}
ABSTRAK
Untuk memenuhi kebutuhan pribadi atau keluaga perubahan pada tempat tinggal adalah salah satu cara yang sering dilakukan. Namun perubahan tersebut tentumya harus di dasari oleh alasan dan pertimbangan yang matang agar hasilnya efisien, sehat, nyaman serta tidak membuang biaya. Artikel ini akan membandingkan dua hunian yang direnovasi dengan fungsi, pendekatan, serta kebutuhan yang berbeda. Temuan penelitian ini diharapkan dapat menjadi bahan evaluasi dan juga pedoman dalam merenovasi rumah.
\end{abstract}

Kata Kunci: Renovasi, Efisiensi, Rumah, Ruang.

Article history: Received 2021-01-26; Revised 2021-03-26; Accepted 2021-04-26;

\section{PENDAHULUAN}

Keterbatasan lahan untuk hunian menjadi salah satu peluang yang dibaca oleh para developer (pengembang) untuk memenuhi kebutuhan hunian di Indonesia. Ketersediaan Rumah tinggal saat ini sangat mudah didapatkan Developer memberikan opsi yang memudahkan konsumen untuk membeli hunian. Kemudahan yang sering dijumpai saat ini yaitu penawaran cicilan pembayaran jangka panjang dengan angsuran yang ringan. Stevanus, Ady Thahir, Indartoyo (2015) menjelaskan adanya indikasi ketidakpuasan dari konsumen terhadap hunian yang disiapkan oleh developer, hal tersebut terlihat dengan adanya perubahan fisik dari bangunan asli yang dirancang dan dibangun oleh developer.

"Dalam merenovasi kita harus mengedepankan aspek fungsi dan kenyamanan terlebih dahulu terhadap klien. Jangan sampai merenovasi malah menjadikan kualitas kenyamanya turun dari bangunan sebelumnya" (Ar. Tomi Saputro, IAI, arsitek praktisi Architama Indonesia, 3 Oktober 2020).

Proses dalam merenovasi bangunan lama memiliki banyak pertimbangan. Pada pertimbanga tersebut perlu diketahui adanya kebutuhan khusus yang mungkin sangat spesifik. Kebutuhan tersebut yang akan di bandingkan dengan ketersediaan ruang yang nantinya akan berpengaruh dengan kualitas kenyamanan. Tentunya fungsi dan kenyamanan adalah tolak ukurnya.

"Renovasi yang dilakukan di perumahan harus di ketahui dua pihak antara pemilik rumah dan pihak pengembang sehingga tidak menimbulkan permasalah dalam perijinan dan juga menurunkan daya jual nama suatu 
perumahan" (Ar. Yanuar Iwan Pandria,IAI, Direktur Architama Indonesia, Oktober 2020).

Dalam proses renovasi juga membutuhkan komunikasi yang baik dengan pihak pengembang. Arsitek perlu bijak dalam pengolahan dan perubahan elemen bangunan karena terkait dengan aturan dan kebijakan pada masing-masing perumahan. Sehingga, proses renovasi tidak memberi dampak negatif kepada pengembang seperti menurunnya nilai jual perumahan. Ar. Yanuar Iwan Pandria (2020) menambahkan, perlu adanya edukasi yang baik terlebih dahulu kepada konsumen terkait batasan renovasi bangunan, terlebih jika renovasi tersebut mempertimbangkan keterbatasan dan biaya.

Tantangan selanjutnya dari proses renovasi bangunan adalah pemanfaatan sisa lahan dan juga efisiensi ruang. Pada umunya perancangan hunian di perumahan hampir memakai $75 \%$ dari luasan kavling, sehingga hanya tersisa sedikit untuk ruang hijau pribadi seperti taman dan carport. Dari sisa lahan tersebut apa bila diperlukan renovasi perluasan, arsitek harus bisa memanfaatkanya dengan baik. Sehingga, penelitian ini diharapkan dapat menjelaskan bagaimana penataan dan efisiensi ruang dalam proses renovasi yang menghasilkan ruang yang efisien, nyaman, aman dan tentunya tidak membahayakan penggunanya. Tujuan penelitian ini untuk mengetahui seberapa efektif metode efiensi ruang pada renovasi rumah tinggal di perumahan dengan membandingkan dua project renovasi rumah tinggal yang berbeda.

\section{TINJAUAN PUSTAKA}

Menurut Undang-undang Nomor 4 Tahun 1992 yang mengatur tentang Perumahan dan Permukiman, menjelaskan bahwa rumah adalah bangunan yang berfungsi sebagai tempat tinggal atau hunian serta sarana bina keluarga. Sementara pengertian perumahan adalah unit rumah dalam jumlah tertentu yang berfungsi sebagai lingkungan tempat tinggal yang dilengkapi dengan prasarana lingkungan, misalnya penyediaan air minum, pembuangan sampah, tersedianya listrik, telepon, jalan, yang memungkinkan lingkungan pemukiman berfungsi sebagaimana mestinya. Hariadi Tama (2016) menjelaskan pertumbuhan perumahan seiring jumlah penduduk yang tinggi saat sekarang ini dengan pertimbangan lokasi site yang terbatas, tingginya harga lahan, dan lokasi yang strategis diperlukan kriteria yang mendukung akan kebutuhan tersebut diantaranya efisiensi pada pemanfaatan lahan bangunan.

Efisiensi dikatakan sebagai komplek perumahan dengan memaksimalkan kebutuhan ruang pada bangunan rumah sehingga memberikan lahan lebih yang dapat dimanfaatkan. Dalam perencanaan perumahan memiliki standar yang telah di terapkan dalam perencanaan dan pembangunan. Standar tersebut lah yang dipakai oleh para pengembang untuk membuat perumahan. Tetapi bila lokasi yang berada di pusat kota, pengembang dihadapi dengan masalah lebih kompleks lagi seperti permintaan para owner yang kebanyakan adalah orang yang sibuk

Kajian Penataan dan Efisiensi Ruang Dalam Renovasi Rumah Tinggal 
bekerja sehingga lebih mementingkan kenyamanan dan privasi di area sekitar tempat tinggal mereka.

Menurut KBBI (Kamus Besar Bahasa Indonesia) Renovasi berarti memberbarui, menyempurnakan, Peremajaan, Perubahan. Kata tersebut sering digunakan dalam konteks bangunan dan konstruksi. Stevanus, Ady Thahir, Indartoyo (2015) memaparkan agar mampu mengakomodasi kebutuhanya, keluarga melakukan perubahan atau merenovasi rumah tempat tinggalnya. Sehingga dapat mencukupi segala aspek kebutuhan yang di inginkan. Ketika tempat tinggal tidak dapat mengakomodir kebutuhan maka perubahan dan penambahan adalah hal yang wajar dilakukan. Nursyarif Agusniansyah dan Kurnia Widiastuti (2016) menjabarkan rumah yang berkembang (Rumah Tumbuh) dapat di kategorikan menjadi dua, yaitu rumah tumbuh vertikal dan rumah tumbuh horizontal. Jika lahanya luas maka memungkinkan untuk penambahan atau perluasan bangunan secara horizontal. Namun jika lahan pada rumah terbatas maka bisa membangun bertumbuh secara vertikal. Pada proses pengembanganya rumah tumbuh dapat dilakukan dengan mendesain denah ruang yang diperlukan secara keseluruhan.

\section{METODE PENELITIAN}

Metode penelitian ini menggunakan metode Studi Kasus dengan mengkomparasi dua sampling produk hasil renovasi rumah tinggal dengan tipe, kebutuhan serta lokasi yang berbeda. Pengumpulan data yang dilakukan dengan metode wawancara, dan observasi langsung di lapangan. Analisis dan hasil penelitian dijabarkan secara deskriptif. Project Pertama menggunakan kode Project-01 dan Project kedua menggunakan kode Project-02.

\section{Project-01}

Project-01 memiliki luas site $182 \mathrm{~m}^{2}$ dan luas bangunan $105 \mathrm{~m}^{2}$. Rumah tersebut merupakan unit satu lantai terbangun dari pengembang perumahan dengan daftar ruang dan spesifikasi teknis sebagai berikut:

Tabel 1. Daftar Ruang dan Spesifikasi Project-01

\begin{tabular}{|c|c|c|}
\hline Nama Ruang & Jumlah & Spesifikasi Teknis \\
\hline Kamar Tidur & 3 & \multirow{8}{*}{$\begin{array}{l}\text { Keramik 60x60, Meja dapur, } \\
\text { Genteng Beton, Cat Jotun atau } \\
\text { Merk Setara, Pintu Jendela Kayu } \\
\text { Sengon.Struktur Beton Bertulang, } \\
\text { pondasi batukali, dinding bata } \\
\text { merah. }\end{array}$} \\
\hline Ruang Keluarga & 1 & \\
\hline Ruang Tamu & 1 & \\
\hline Kamar mandi luar & 2 & \\
\hline Kamar mandi dalam & 1 & \\
\hline Dapur & 1 & \\
\hline Teras & 2 & \\
\hline Carport & 1 & \\
\hline
\end{tabular}

Sumber : Architama Indonesia, 2020 


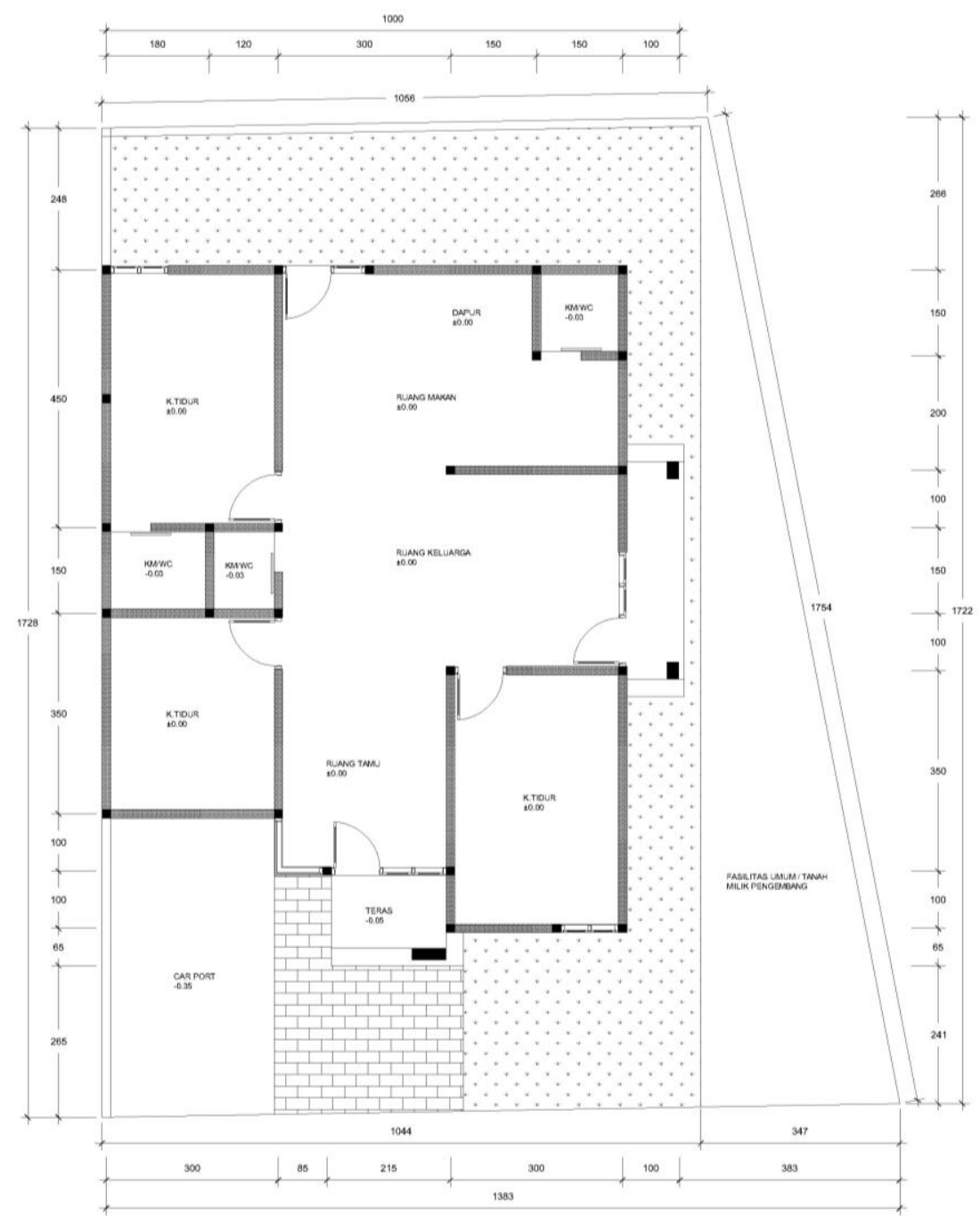

Gambar 1. Denah Eksisting Project-01

Sumber : Architama Indonesia,2020

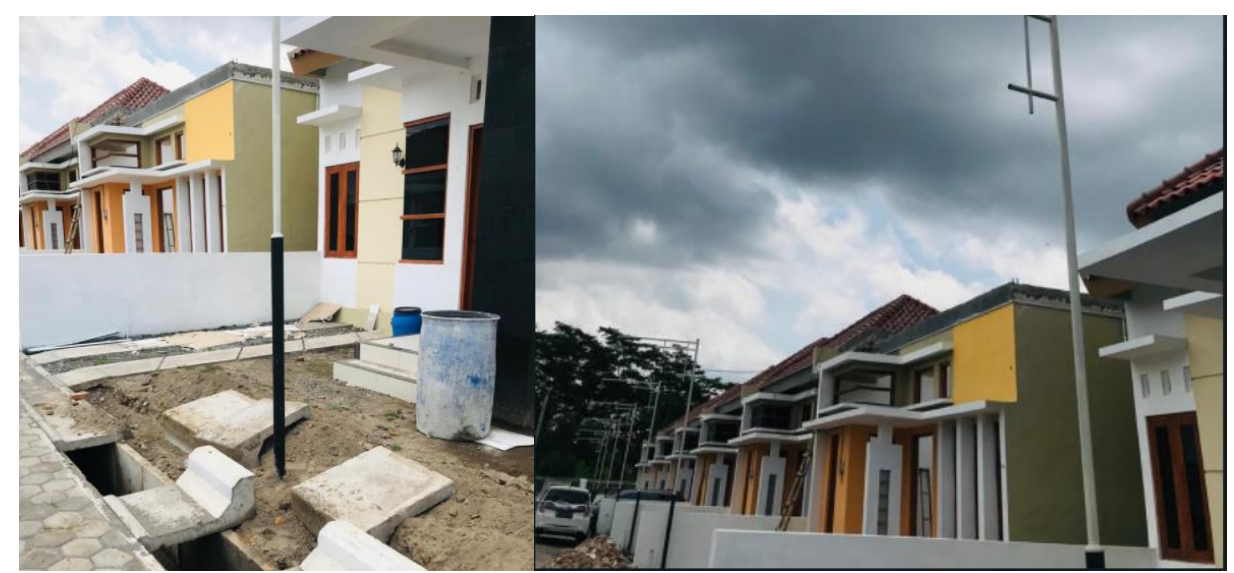

Gambar 2. Foto Eksisting Project-01

Sumber: Baharudin Yusuf Subagya-Praktek Kerja 2020

Kajian Penataan dan Efisiensi Ruang Dalam Renovasi Rumah Tinggal 
Tabel 2.Daftar Penambahan Ruang dan Item Renovasi Project-01

\begin{tabular}{lcl}
\multicolumn{1}{c}{ Nama Ruang } & Jumlah & \multicolumn{1}{c}{ Pengguna } \\
\hline Kamar tidur pembantu & 2 & Sopir dan Pembantu \\
\hline Dapur Kotor & 1 & Pembantu \\
\hline Mushola & 1 & Semua Keluarga \\
\hline Kolam Ikan & 1 & Semua Keluarga \\
\hline Tempat Cuci dan Jemur & 1 & Pembantu \\
\hline Canopi Carport & 1 & Semua keluarga \\
\hline Pagar & 1 & - \\
\hline \multicolumn{3}{l}{ Sumber : Architama Indonesia, 2020 }
\end{tabular}

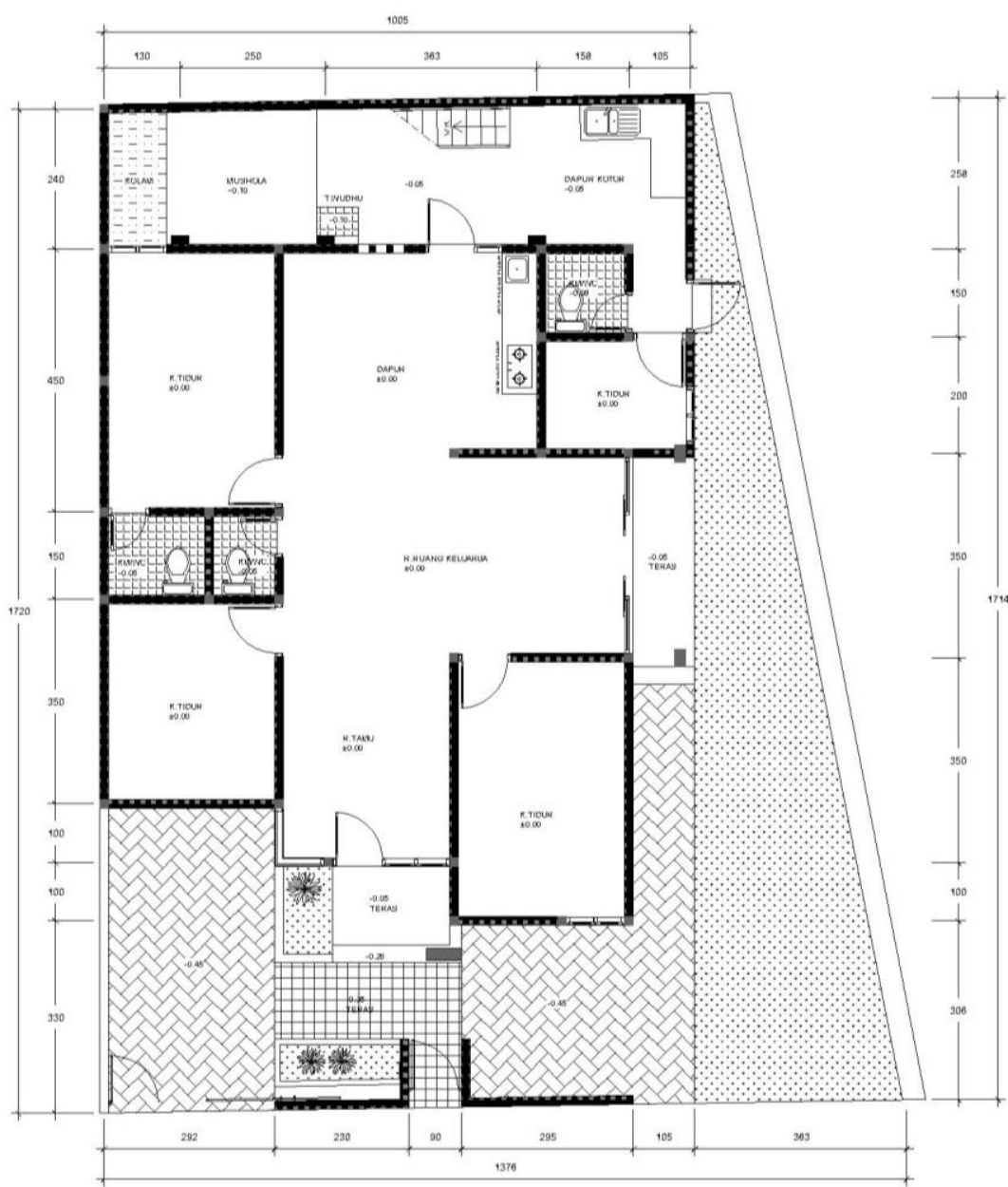

Gambar 3. Denah Perubahan Rencana Renovasi Project-01 Lantai 1

Sumber : Data Project-Architama Indonesia, 2020 


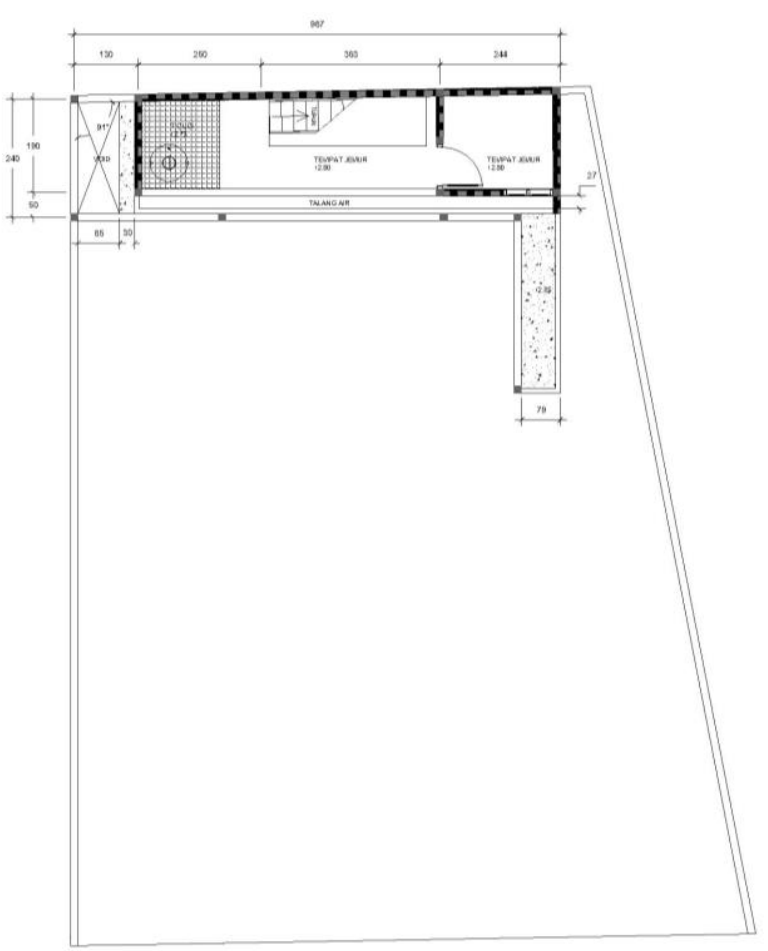

Gambar 4. Denah Perubahan/ Rencana Renovasi Project-01 Lantai 2 Sumber : Data Project-Architama Indonesia, 2020

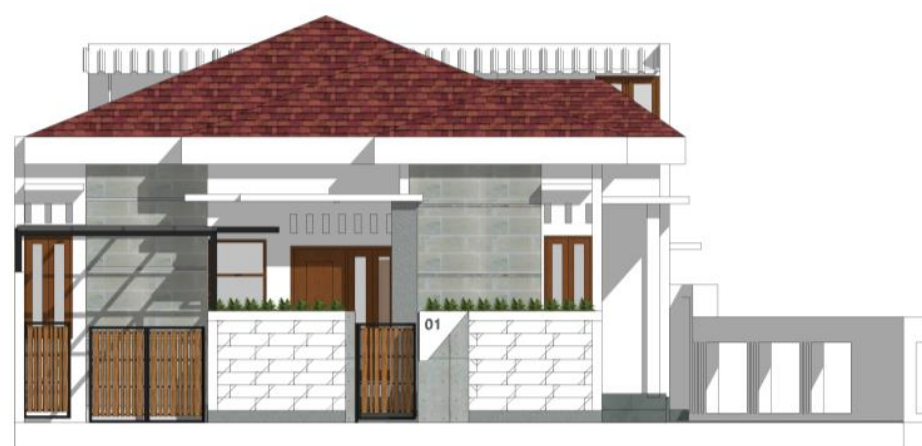

Gambar 5. Tampak Selatan Renovasi Project-01 Sumber : Data Project-Architama Indonesia, 2020

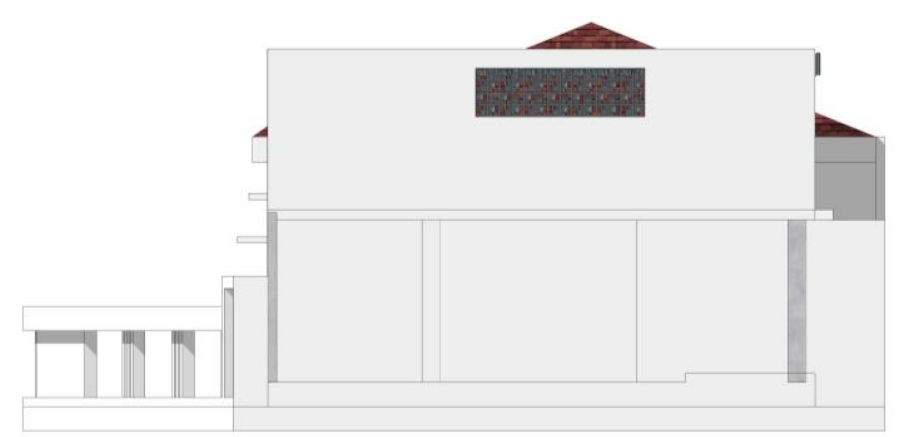

Gambar 6. Tampak Utara Renovasi Project-01 Sumber : Data Project-Architama Indonesia, 2020

Kajian Penataan dan Efisiensi Ruang Dalam Renovasi Rumah Tinggal 


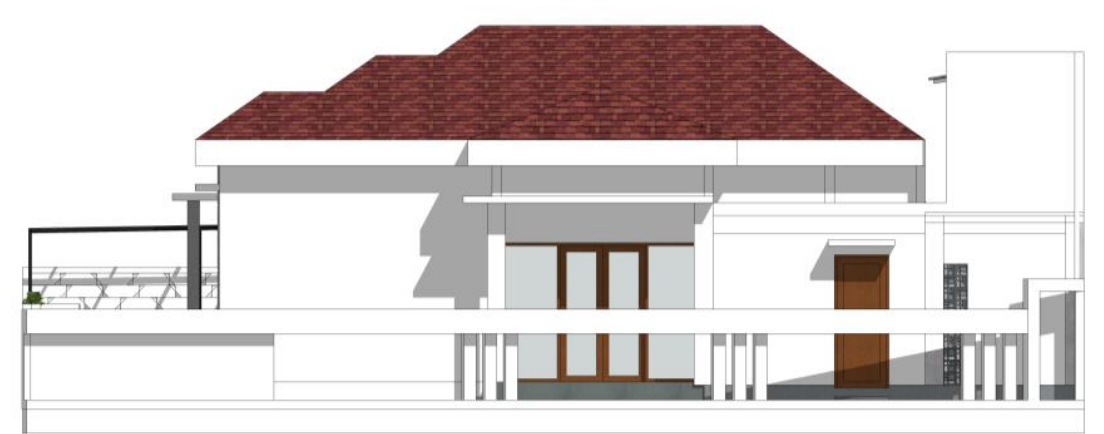

Gambar 7. Tampak Timur Renovasi Project-01

Sumber : Data Project-Architama Indonesia, 2020

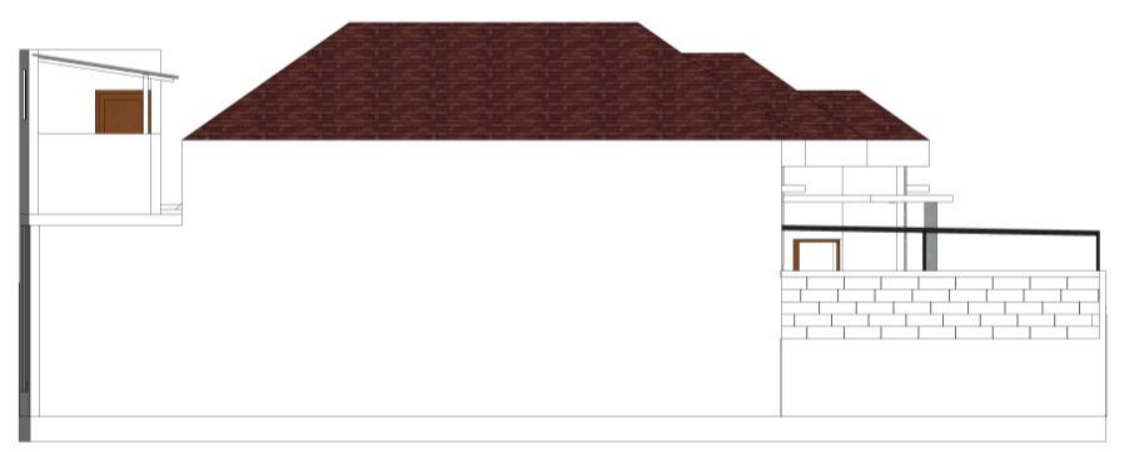

Gambar 8. Tampak Barat Renovasi Project-01

Sumber: Data Project-Architama Indonesia, 2020

Untuk mengkomodir permintaan pemilik untuk tidak ingin menambah jumlah lantai di atas bangunan eksisting maka penambahan ruang disiasati dengan pengolahan ruang di halaman yang tersisa. Halaman belakang hanya memiliki sisa luasan $28,61 \mathrm{~m}^{2}$, hal tersebut menjadi tantangan bagi tim perancang untuk dapat tetap mengakomodiri kebutuhan perancangan dan solusi terhadap batasan yang diberikan oleh pihak pengembang.

Tabel 3. Perubahan Denah Pada renovasi Project-01

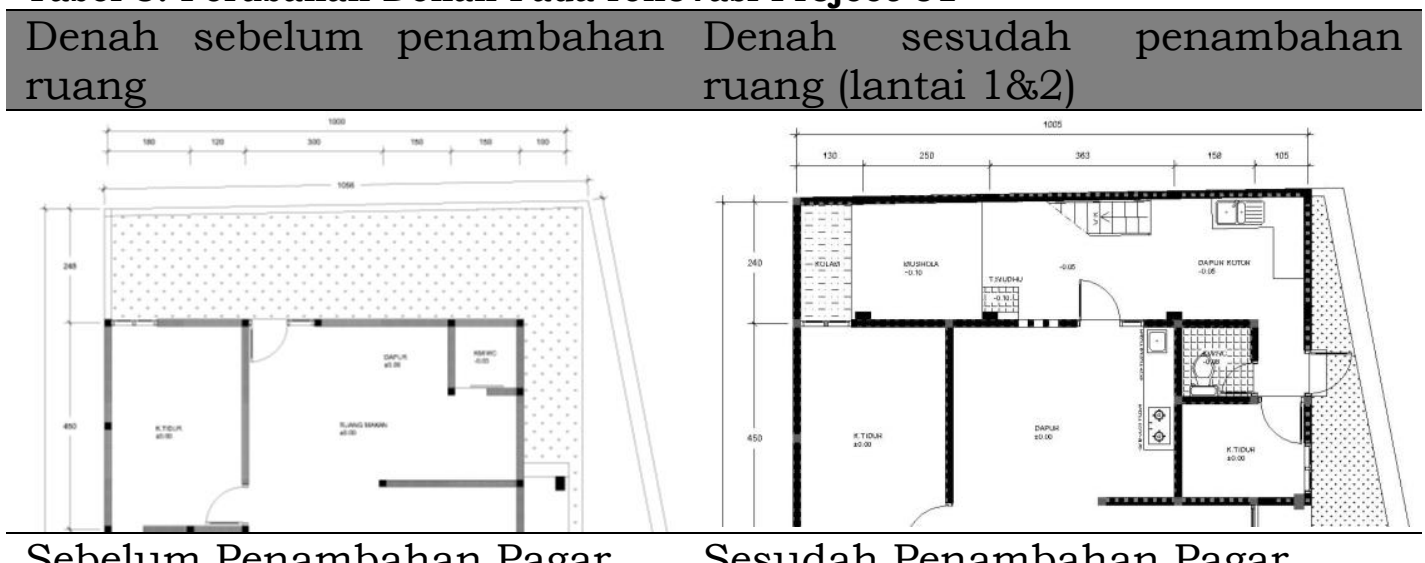

Sebelum Penambahan Pagar Sesudah Penambahan Pagar 

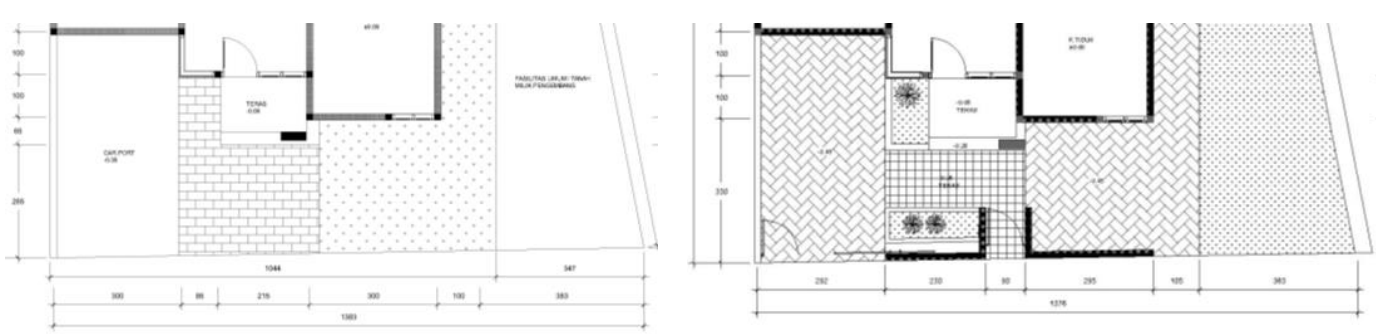

Sumber : Data Project-Architama Indonesia, 2020

\section{Project-02}

Project-02 adalah unit dengan luas tanah sebesar $92 \mathrm{~m}^{2}$ dan luas bangunan sebesar $52 \mathrm{~m}^{2}$ (diluar carport). Project 02 merupakan unit dengan 2 lantai terbangun dengan spesifikasi sebagai berikut :

Tabel .4 Daftar Ruang dan Spesifikasi Project-02

Nama Ruang

\begin{tabular}{ll}
\hline Kamar Tidur & 3 \\
\hline Dapur & 1 \\
\hline Ruang Tamu & 1 \\
\hline Teras Kecil & 2 \\
\hline Ruang Keluarga & 1 \\
\hline Kamar Mandi & 1 \\
\hline
\end{tabular}

Sumber : Architama Indonesia, 2020

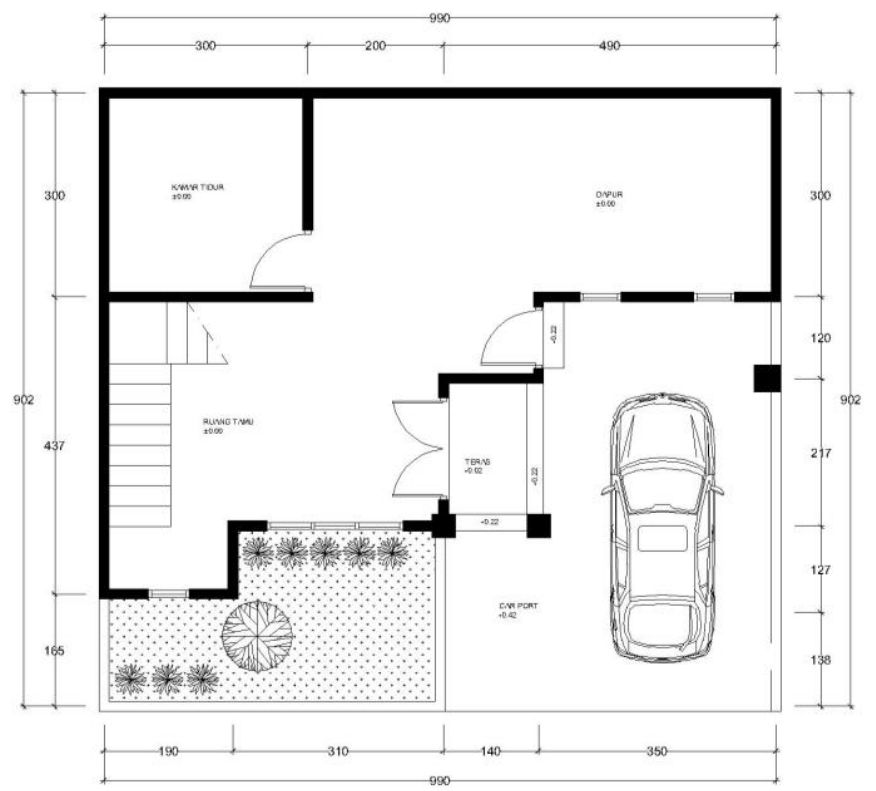

Gambar 9. Denah Eksisting Project-02 lantai 1

Sumber : Data Project-Architama Indonesia, 2020 


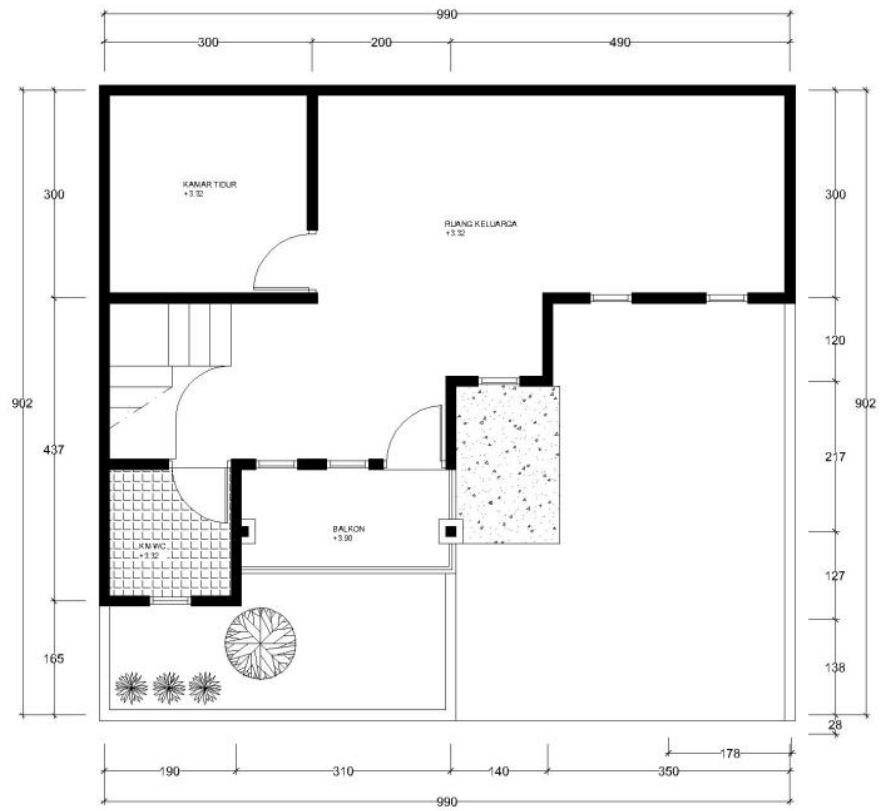

Gambar 10. Denah Eksisting Project-02 lantai 2 Sumber : Data Project-Architama Indonesia, 2020

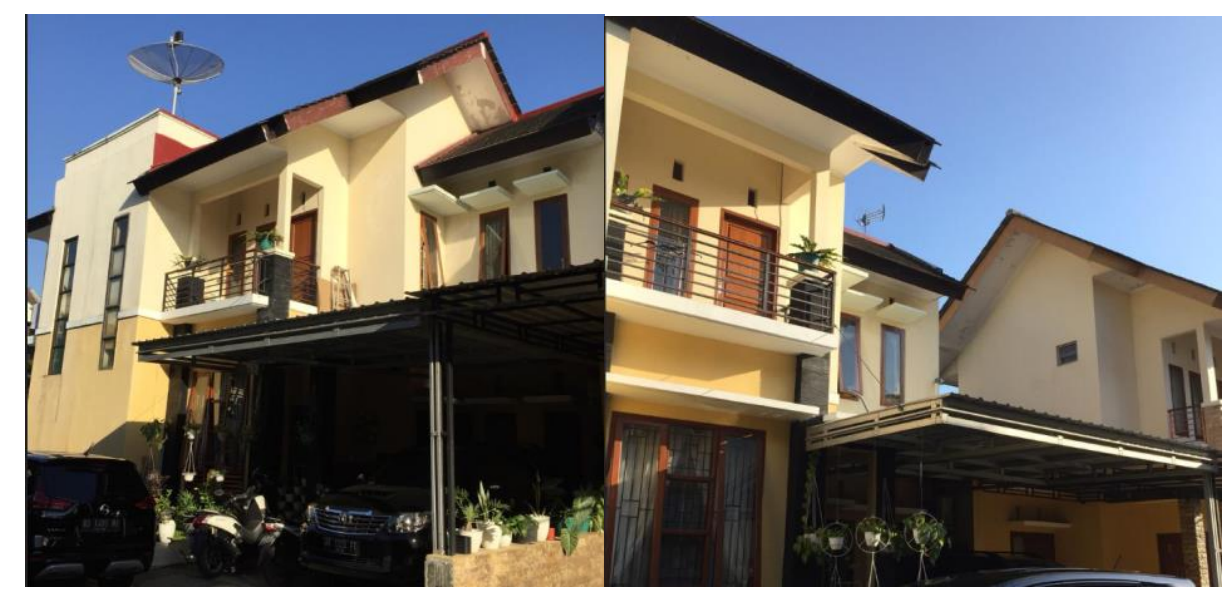

Gambar 11. Foto Eksisting Project-02

Sumber : Data Project-Architama Indonesia, 2020

Tabel 2.2 Daftar Penambahan Ruang dan Item Renovasi Project-01

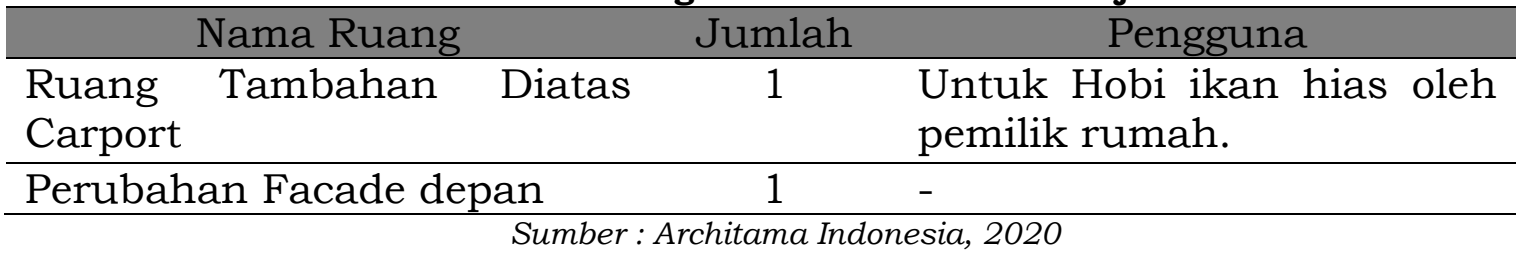




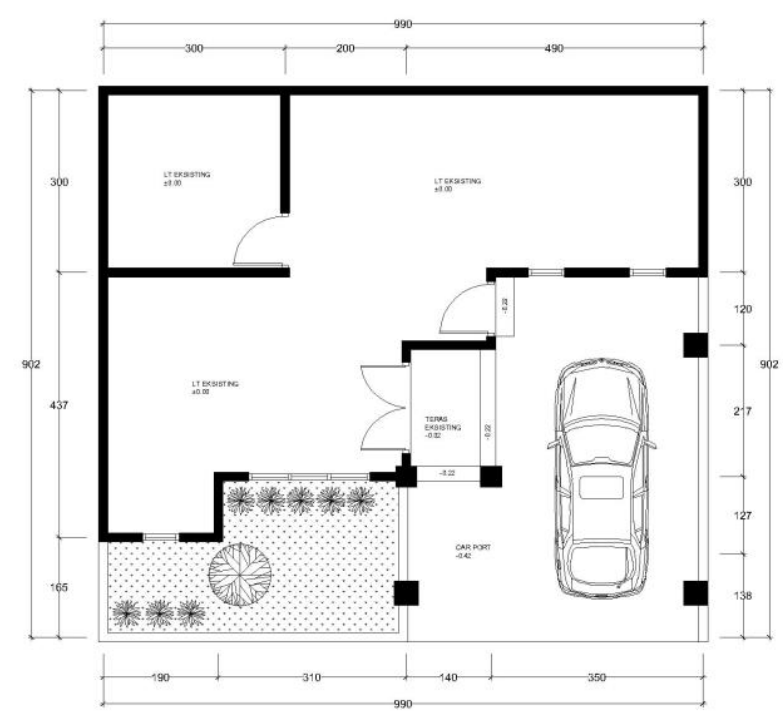

Gambar 12. Denah Renovasi Project-02

Sumber : Data Project-Architama Indonesia, 2020

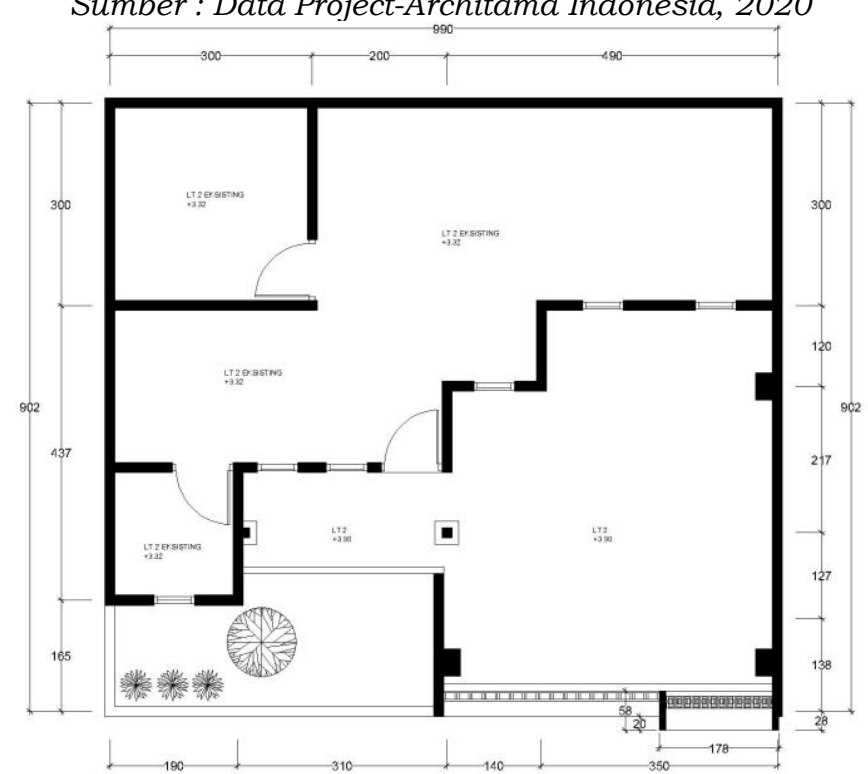

Gambar 13. Denah Renovasi Renovasi Project-02

Sumber : Data Project-Architama Indonesia, 2020

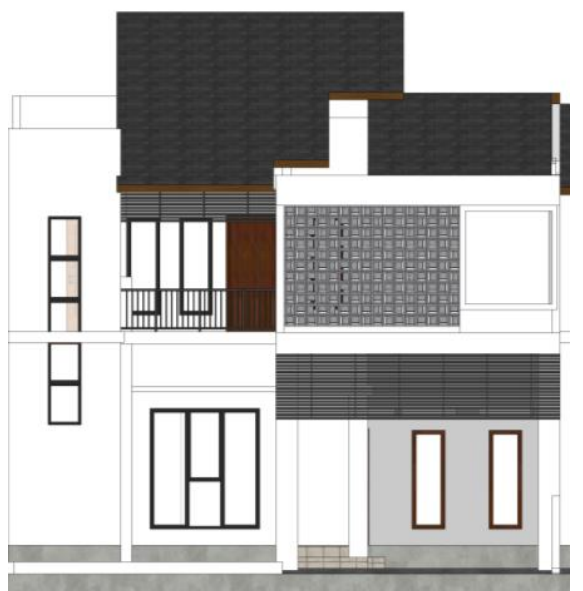

Gambar 14. Tampak Depan Renovasi Project-02

Sumber : Data Project-Architama Indonesia, 2020

Kajian Penataan dan Efisiensi Ruang Dalam Renovasi Rumah Tinggal 


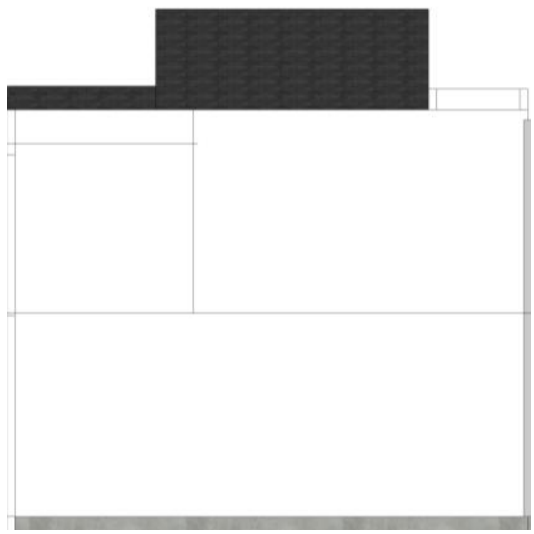

Gambar 15. Tampak Belakang Renovasi Project-02

Sumber : Data Project-Architama Indonesia, 2020

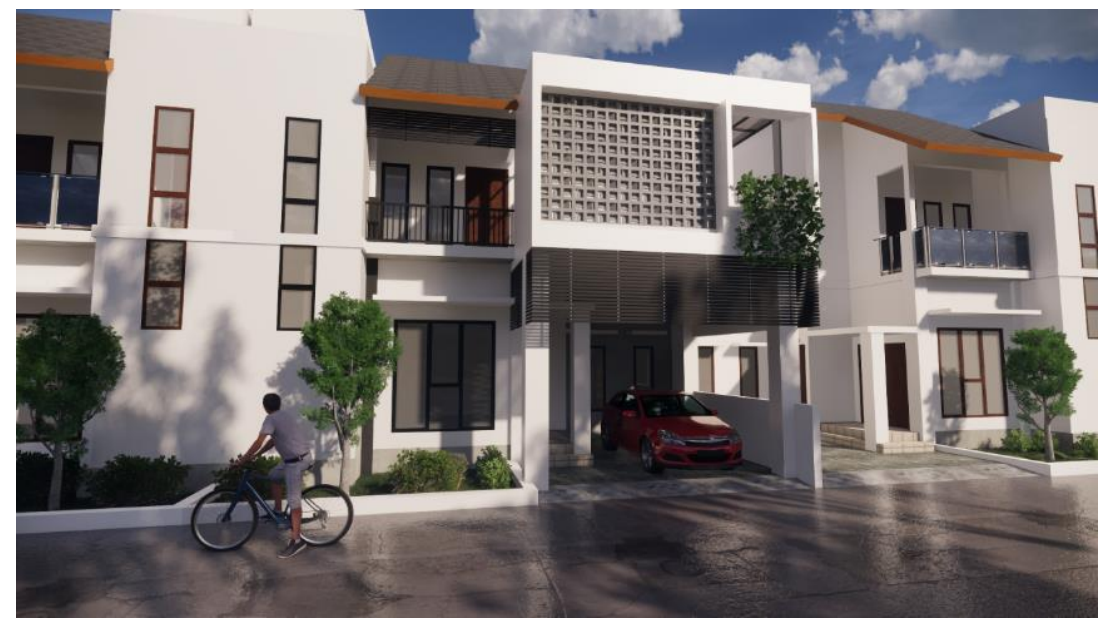

Gambar 16. Prespektif Render Renovasi Project-02

Sumber : Data Project-Architama Indonesia, 2020

Renovasi yang dilakukan untuk Project-02 menghasilkan penambahan luas sekitar $35 \%$ yaitu dari luas bangunan awal $52 \mathrm{~m}^{2}$ menjadi $80 \mathrm{~m}^{2}$. Jika di bandingkan dengan luasan tanah yaitu $92 \mathrm{~m}^{2}$ maka persentasenya adalah 86,9\% terbangun. Desain beradaptasi dengan luasan baru agar desain hunian menjadi lebih privat bagi keluarga tanpa mengurangi optimalisasi cahaya masuk ke dalam bangunan.

\section{PEMBAHASAN DAN HASIL PENELITIAN}

Renovasi rumah tinggal menjadi salah satu solusi dalam pemenuhan bagi pemilik. Namun, dalam proses renovasi, perlu perencanaan yang matang dan mempertimbangkan berbagai aspek mulai dari aksesbilitas, kenyamanan, biaya, keselamatan serta kesehatan penggunanya. Kedua produk desain yaitu Project-01 dan Project-02 memiliki kebutuhan serta tantangan yang berbeda. Project-01 merupakan hunian yang melakukan tindakan renovasi dari tahap awal pembelian dengan pihak pengembang, tim perancang mengikuti proses renovasi dari tahapan awal. Sedangkan Project-02 merupakan hunian yang sudah digunakan, kemudian dilakukan

Kajian Penataan dan Efisiensi Ruang Dalam Renovasi Rumah Tinggal 
renovasi. Keduanya memiliki tingkat efisiensinya berbeda dengan adanya banyak faktor dan keterbatasan.

\begin{tabular}{|c|c|}
\hline Project-01 & Project-02 \\
\hline $\begin{array}{l}\text { Gambar 17. Prespektif Render Renovasi } \\
\text { Project-01 } \\
\text { Sumber : Data Project-Architama Indonesia, } 2020\end{array}$ & $\begin{array}{l}\text { Gambar 18. Prespektif Render Renovasi } \\
\quad \text { Project-02 } \\
\text { Sumber: Data Project-Architama Indonesia, } 2020\end{array}$ \\
\hline Rumah Baru (belum dihuni) & Rumah yang sudah dihuni \\
\hline Luas Tanah : $182 \mathrm{~m}^{2}$ & Luas Tanah : $92 \mathrm{~m}^{2}$ \\
\hline Luas Bangunan : $105 \mathrm{~m}^{2}$ & Luas Bangunan : $52 \mathrm{~m}^{2}$ \\
\hline Jumlah Lantai : 1 & Jumlah Lantai : 2 \\
\hline $\begin{array}{l}\text { Peningkatan luasan setelah } \\
\text { renovasi : } 22.3 \%\end{array}$ & $\begin{array}{l}\text { Peningkatan luasan setelah } \\
\text { renovasi : } 35 \%\end{array}$ \\
\hline $\begin{array}{l}\text { Luas bangunan setelah di renovasi : } \\
135 \mathrm{~m}^{2}\end{array}$ & $\begin{array}{l}\text { Luas bangunan setelah di renovasi : } \\
80 \mathrm{~m}^{2}\end{array}$ \\
\hline $\begin{array}{l}\text { Alsan Merenovasi : Kebutuhan } \\
\text { servis dan fasilitas penunjang }\end{array}$ & $\begin{array}{l}\text { Alsan Merenovasi : Keinginan } \\
\text { pemilik, bukan kebutuhan primer. }\end{array}$ \\
\hline
\end{tabular}

\section{Efisiensi Project-01}

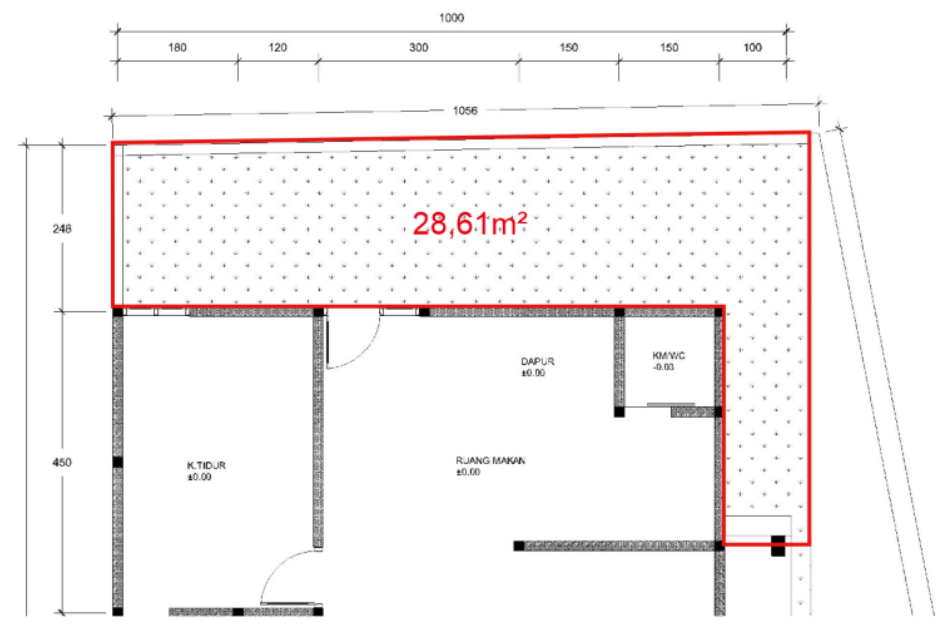

Gambar 19. Luasan Sisa Lahan

Sumber : Data Project-Architama Indomesia 2020

Dengan batasan brief yaitu hanya dapat mengolah halaman belakang dengan luasan $28,61 \mathrm{~m}^{2}$, maka prioritas utama pada penambahan ruang 
adalah area servis seperti dapur kotor dan area cuci. Pengguna paling dominan pada area tersebut adalah asisten rumah tangga. Pertimbangan yang matang dibutuhkan untuk dapat mencapai efisiensi yang diharapkan. Salah satu metodenya adalah dengan mengoptimalisasi letak ruang.

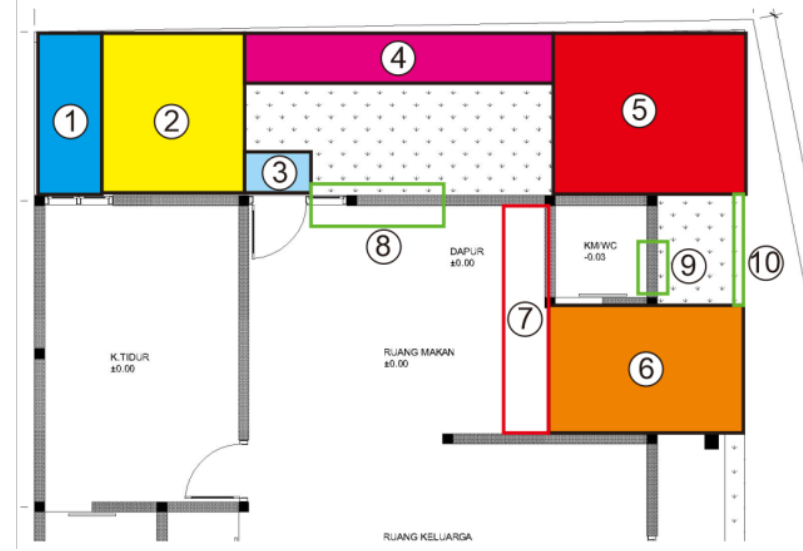

Gambar 20. Pembagian zona Project-01 Lanai 1

Sumber: Data Project-ArchitamaIndomesia 2020

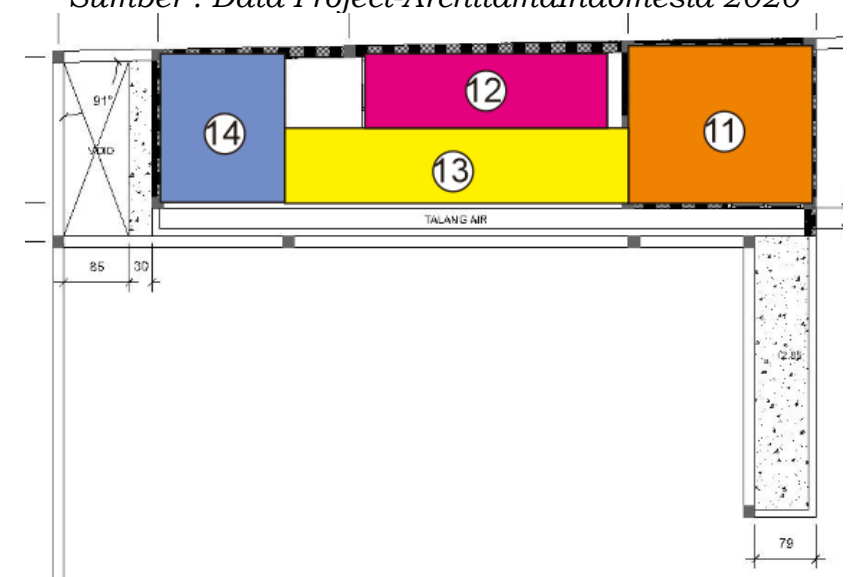

Gambar 21. Pembagian zona Project-01 Lanai 2

Sumber : Data Project-ArchitamaIndomesia 2020

Keterangan Gambar 4.2 dan 4.3 :

1. Kolam ikan di letakan di paling ujung untuk membuat void (lubang tembusan dari lantai I ke 2 bisa juga tidak beratap) agar cahaya dan udara bisa masuk.

2. Mushola ditempatkan bersebelahan dengan kolam ikan, hal ini adalah permintaan dari pemilik rumah. Mushola tidak punya sekat pemisah hanya dibedakan oleh elevasi yang lebih tinggi.

3. Tempat wudhu kecil bersebelahan dengan mushola dibedakan oleh elevasi yang turun dan keramik yang berbeda.

4. Tangga menuju Lantai 2 atau tempat cuci. Dibawah tangga digunakan sebagai meja setrika untuk mengoptimalkan ruang yang ada agar tidak terbuang.

5. Dapur kotor, sama halnya dengan mushola tidak memiliki sekat apapun hanya meja dapur seperti biasa. 
6. Kamar tidur pembantu, luasanya menesuaikan dengan sisa antara kamar mandi pada dapur hingga ke dinding ruang keluarga. Aturan baku yang menjadi prinsip ruang ini adalah adalah muat untuk kasur dan juga sebuah lemari untuk menyimpan pakaian.

7. Perubahan kichenset pada dapur bersih yang semula ada diatas bersebelahan dengan pintu eksisting. Karena pintu dipindahkan maka kitchenset dipindah.

8. Pintu eksisting dipindah bergeser menjadi ke tengah.

9. Pintu kamar mandi baru, dikarenakan pintu lama akan di tutup karena langsung terakses oleh kamar pembantu.

10. Dinding baru dan Pintu baru yang langsung menuju ke luar atau bisa dikatakan adalah pintu belakang.

11. Kamar tidur pembantu yang juga bertugas sebagai supir pribadi. Pakem yang diambil masih sama dengan yang sebelumnya yaitu muat dengan ukuran kasur untuk satu orang dan juga lemari kecil.

12. Void tangga atau ruang untuk tangga.

13. Jalan akses menuju kamar nomor 11 sekaligus adalah tempat jemur pakaian.

14. Tempat mesin cuci dan tangki air.

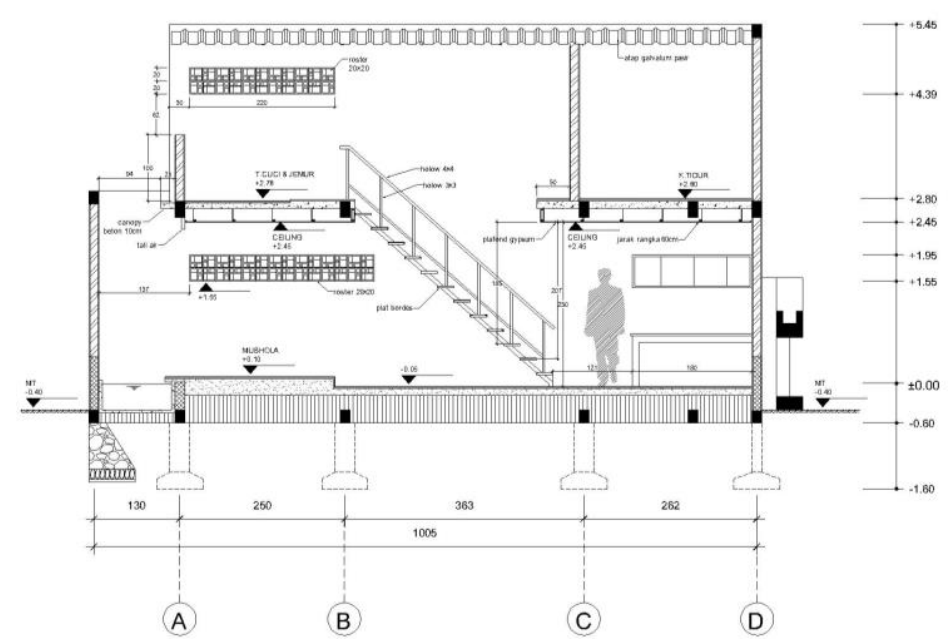

Gambar 22. Potongan Gambar Kerja Project-01

Sumber : Data Project-Architama Indomesia 2020 


\section{Efisiensi Project-02}

Target yang ingin di capai untuk Project-02 adalah memenuhi kebutuhan dan aktivitas tambahan yang diharapkan oleh pemilik rumah dan berfungsi sebagai carport.

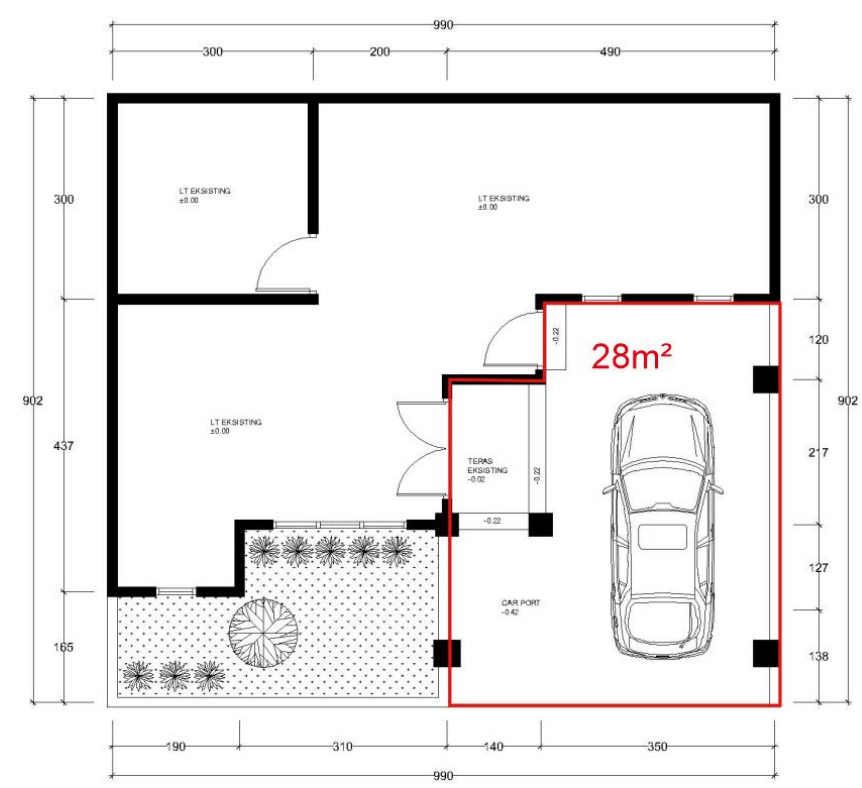

Gambar 23 Luasan Sisa Lahan Project-02

Sumber : Data Project-Architama Indomesia 2020

Luasan tambahan untuk Project-02 adalah $28 \mathrm{~m}^{2}$ seperti di gambar 23. Tantangan dalam desain ini adalah desain tetap maksimal dengan pertimbangan struktur yang kuat untuk menopang plat lantai diatasnya.

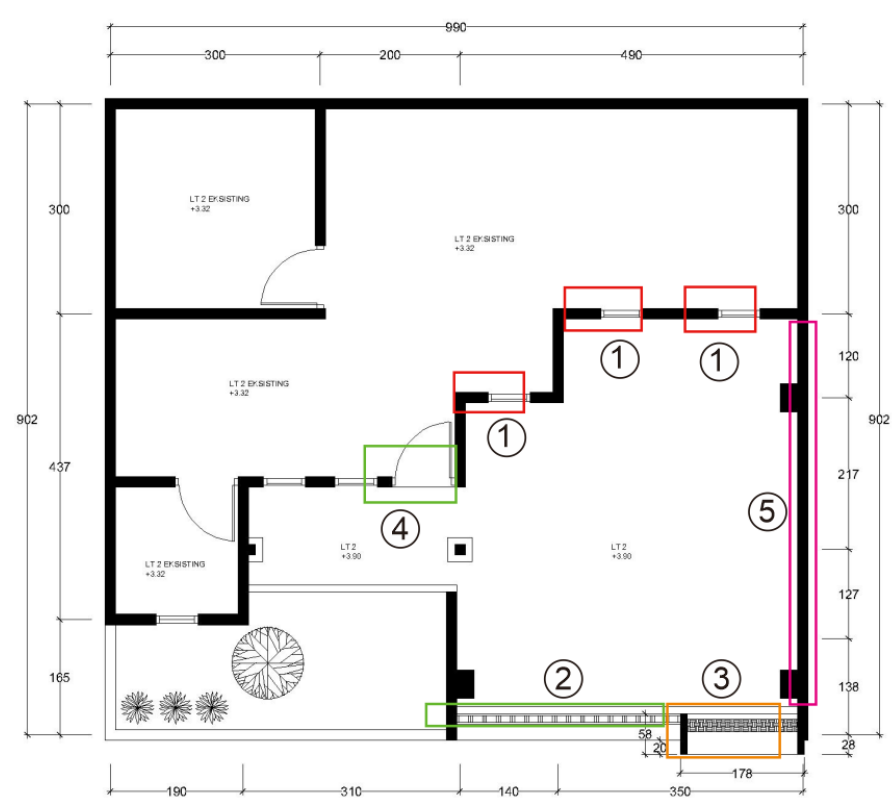

Gambar 24. Luasan Sisa Lahan Project-02

Sumber : Data Project-Architama Indomesia 2020

Keterangan Gambar 24 :

Kajian Penataan dan Efisiensi Ruang Dalam Renovasi Rumah Tinggal 
1. Jendela Eksisting yang masih yang tidak di bogkar karena keterbatasan biaya untuk mengganti ventilasi namun masih dapat dipakai untuk memasukan cahaya alami. (akan di jelaskan pada nomor 2 dan 3 )

2. Roster yang di pasang full dari bawah sampai ke atas untuk memasukan cahaya dan udara. Selain itu rosterjuga menjadi pemanis facade.

3. Bukaan full dengan pot tanaman agar cahaya lebih optimal masuk.

4. Akses satu-satunya dari lantai 2, sebenarnya dari pihak perencana menganjurkan untuk memasang pintu lagi di bagian deretan jendela nomor 1. Namun karena keterbatasan biaya akhirnya tetap menggunakan akses satu-satunya tersebut.

5. Dinding baru digunakan untuk menangkal panas dari arah barat.

Brief untuk tim perancangan dalam mendesain Project 02 adalah pertama penambahan ruang baru dengan akses sanitasi, drainase, dan listrik yang baik untuk renovasi tersebut. Kedua, aplikasi fasad bangunan dengan pemilihan material yang baik untuk finishing baik dalam maupun luar bangunan dan tetap bersinergi dengan fasad bangunan lama.

Dari kedua studi kasus tersebut, penulis dapat merujuk bahwa tim Arsitek hendaknya dapat merekomendasi desain yang mengakomodir kebutuhan dan aktivitas pengguna.

"Pertimbangan-pertimbangan yang ada dan kelebihan kekurangan hendaknya harus di utarakan kepada pengguna seluruhnya, agar pemilik juga tau apa keputusan dan jalan tengah yang di ambil” (Ar. Yanuar Iwan Pandria,IAI, Direktur Architama Indonesia, Oktober 2020).

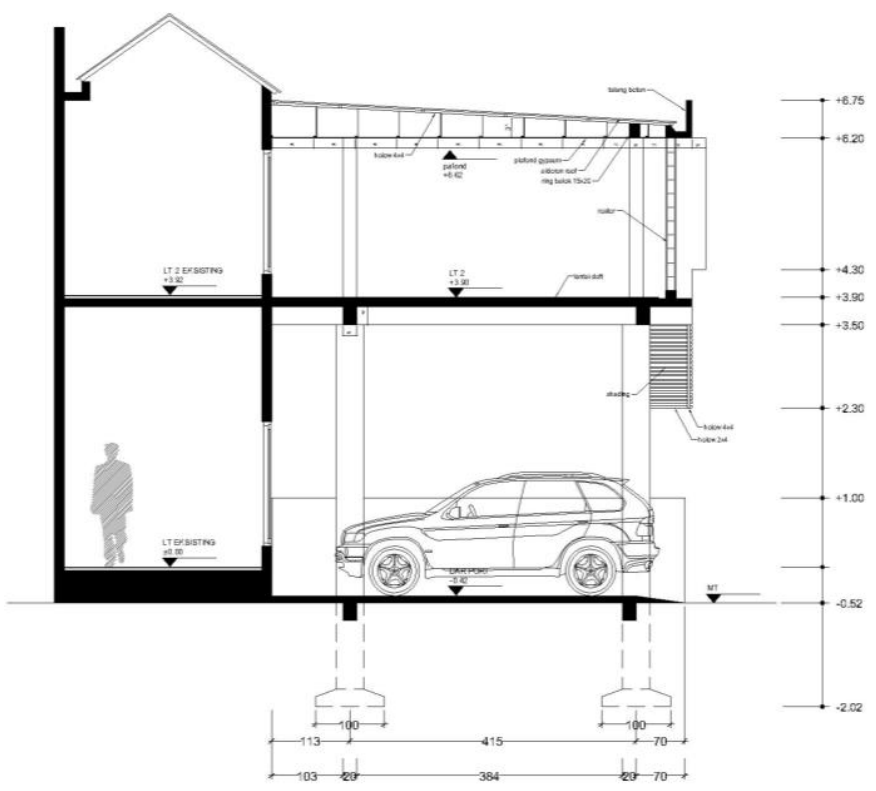

Gambar 25. Luasan Sisa Lahan Project-02

Sumber : Data Project-Architama Indomesia 2020

Kajian Penataan dan Efisiensi Ruang Dalam Renovasi Rumah Tinggal 


\section{SIMPULAN}

Renovasi tidak hanya merubah atau menambah ruang pada suatu bangunan. Dengan membandingkan Project-01 dan Project-02, dapat dilihat bahwa sebuah renovasi mempunyai pendekatan, kebutuhan dan fungsi yang berbeda. Seberapa berhasilnya renovasi di tentukan dengan tercapainya pemenuhan kebutuhan atau keinginan penghuninya. Tentunya semua itu harus di selaraskan dengan kenyamanan, keselamatan serta kesehatan penggunanya. Faktor biaya juga menjadi pertimbangan tambahan yang bisa matangkan terlebih dahulu sebelum mulai merenovasi. Ada kalanya kita harus lebih menghargai sebuah ruang karena dengan menghargai ruang kita bisa lebih mensyukuri dan mensiasati rasa kekurangan yang ada.

\section{DAFTAR RUJUKAN}

Danniel Stevanus. 2015. Studi Perubahan FungsiRuang Pada Unit Rumah Tinggal Di Cluster Orlando Dan Georgia, Kota Wisata Cibubur. AGORA Jurnal Arsitektur Volume 15 (hlm. 13-14)

Hariadi Tama 2016. Perumahan Pusat Kota Dengan Konsep Evisiensi Di Pontianak. Jurnal Online Mahasiswa Arsitektur Universitas Tanjung Pura. Volume 4 (hlm. 11)

Kurnia Agusniansyah. 2016. Konsep Pengolahan Desain Rumah Tumbuh. Volume (hlm. 1-2)

Rully. 2014 Merencanakan dan Merancang Rumah Tinggal yang Optimal. Jurnal Elektronik Universitas Tunas Pembangunan Surakarta.

Undang-undang Republik Indonesia Nomor 4 tahun 1992 tentang Perumahan dan Permukiman.

Kamus Besar Bahasa Indonesia (KBBI) web Online versi 2.8 edisi III tahun 2019. 